\title{
SHPIS: A Database of Medicinal Plants from Saudi Arabia
}

\author{
Asif Hassan Syed \\ Department of Computer Science, Faculty of Computing \\ and Information Technology at Rabigh (FCITR), \\ King Abdulaziz University \\ Jeddah, Saudi Arabia
}

\author{
Tabrej khan \\ Department of Information Sciences, Faculty of Computing \\ and Information Technology at Rabigh (FCITR), \\ King Abdulaziz University \\ Jeddah, Saudi Arabia
}

\begin{abstract}
Many studies in the past have revealed the use of the indigenous medicinal plant for the treatment of various diseases in Saudi Arabia. However, the details of these indigenous essential medicinal herbs and their therapeutic implication against various human and animals diseases are not well documented and organised in a local platform. In this regard, a thorough mining of scholarly article for information on local herbal remedies available and used by communities of Saudi Arabia was performed. The research revealed a unique insight into the natural herbal resource of Saudi Arabia with as many as 120 varieties of the medicinal plant from Saudi Arabia. Therefore, in order to provide a structured platform to store and retrieve relevant information pertaining to an indigenous medicinal plant of Saudi Arabia, a Saudi Herbal Plants Information System was built using waterfall model. MySQL an open source Relational Database Management System and server-side scripting language Hypertext Pre-processor was used to build an interactive dynamic web portal of the Saudi Herbal Plants Information System. The designed web portal allows visitors to access information on herbs available in the herbal database for research and development.
\end{abstract}

Keywords-Saudi Medicinal Plants; Saudi Herbal Plant Information System; MySQL; Relational Database Management System; Hypertext Pre-processor; Web Portal

\section{INTRODUCTION}

The use of medicinal plants as a source of therapy against various ailments have been practiced in Saudi Arabia since ages [1]. Studies in the past have reported the presence of valuable medicinal plants from the different regions of Saudi Arabia [2-9]. However, the information of the indigenous medicinal plants of Saudi Arabia is scattered in a disorganised manner. Therefore, our objective in this study was to build a manually curated information system constituting of the information specifically of medicinal plants found in the Kingdom of Saudi Arabia. In the past, scientists/researchers of countries like Bangladesh, China, Hong Kong, India, and Pakistan have built herbal database comprising of herbal plants found in their respective countries, namely, Medicinal Plants of Bangladesh (http://www.mpbd.info), Chinese Herbal Medicine Database (http://herbaltcm.sn.polyu.edu.hk), Indian Medicinal Plants Database (http://www.medicinalplants.in), Medicinal Plants of Pakistan (http://old.parc.gov.pk/Data/Medicinal/medsearch.asp). The basic requirement of building an herbal database by countries like Bangladesh, China, Hong Kong, India, and Pakistan is to organise and enlist their herbal heritage for the development of an alternative medicine source.

In this context, the present Saudi herbal information system was developed using waterfall method since the requirements of Saudi Herbal Plants Information System (SHPIS) were well defined [10-11]. Moreover, waterfall method is a well-known software engineering method with a lot of advantages [12-14]. MySQL (www.mysql.com) an open source Relational Database Management System (RDBMS) that uses structured Query language (SQL), was used for managing the content of SHPIS. The web portal of SHPIS was developed using the Hypertext Preprocessor (PHP) a server-side scripting language (www.php.net).

SHPIS will provide a manually curated information of as many as 120 unique varieties of the medicinal plants from the Kingdom of Saudi Arabia. The SHPIS is designed to store the local name, scientific name, family name, part used for medicinal purpose and traditional usage for treating various diseases and sickness, such as skin allergy, epilepsy, diabetes, asthma, rheumatism, stomach problems, constipation, ear and eye problem, urinary and bladder diseases, measles, cold, fever, toothache, etc. The web portal will also be a leap forward in generating understanding among the Saudi nationals of their glorious medicinal herbal legacy. All the data relevant to Saudi herbal plants is available online at http://www.SHPIS.com.

The later part of the manuscript is organised as Section 2 which presents an elaborate description of the methodology employed for data collection, curation and construction of the herbal database. In Section 3, the results of database design, implementation, user interface, visualization, testing, maintenance, comparative analysis of SHPIS with the current medicinal plant databases and future development plan of SHPIS are discussed. Section 4 report the conclusion of the present research work.

\section{MATERIALS AND METHOD}

\section{A. Database content and Construction}

\section{1) Data sources and curation}

A catalog of medicinal plants available in Saudi Arabia was prepared from the past studies of several researchers [2-9]. The exact information, namely, the family name, scientific name, local name, disease treated and the part used for the treatment of each medicinal herb submitted in SHPIS were manually 
curated from information available in the literature. Highresolution images of the medicinal plants available in the web without restriction for academic use were used to pictorial display; medicinal herbs are present in SHPIS. The SHPIS identifies a total of 120 medicinal herbal plants found in Saudi Arabia and possibly making it a most comprehensive database of Saudi Medicinal herbal plants (Table 1).

\section{TABLE I. SHPIS DATABASE INFORMATION}

\begin{tabular}{|l|l|}
\hline Number of Herbal Plant & $\mathbf{1 2 0}$ \\
\hline Family wise distribution & $\mathbf{5 9}$ \\
\hline
\end{tabular}

SHPIS provides the facility to curate information of medicinal plants present in the database by curator team (admin) as well as other researchers (visitors of the website). Like for example, the curator team can add, edit or delete plant name, traditional usage of herbal plants and the name of the part of medicinal plants used for the treatment of various diseases. Similarly, the researcher visiting the website can modify or add to the existing content of database by providing proper citations or references of the same. The data obtained or modified by the researcher will be authenticated by the administrator of SHPIS. Upon authentication, the valid information provided by the researcher will be incorporated into the database. This characteristic feature of the SHPIS shall allow the growth of the database in terms of size and information as more and more information related to medicinal plants of Saudi Arabia are explored or discovered by researcher across the globe.

\section{2) Database architecture}

We developed a database information system, named SHPIS, to store manually curated data of all medicinal plants found in the Kingdom of Saudi Arabia. The waterfall method was used for the development of SHPIS. The waterfall method typically consists of five phases [12] as shown in Figure 1. The Unified Modelling Language (UML) ver. 2.0 was used as a modelling language in the early stages of the waterfall model. In the implementation phase, Model-view-controller (MVC) architecture was used to develop the web application and database of the SHPIS, respectively. MVC consist of three interconnected parts, namely, (1) model, (2) view, and (3) controller. The model consists of MySQL, an open source RDBMS used for managing the content of SHPIS. A dynamic user-friendly web portal of SHPIS was developed using HTML for any data query and output representation of information for analysis. The last part, the controller, receives input and transforms it to command for either model or view using PHP the server-side scripting language. The functionality and internal structure of the information system were tested using black-box and white-box, respectively and the resulted system was hosted on http://www.SHPIS.com.

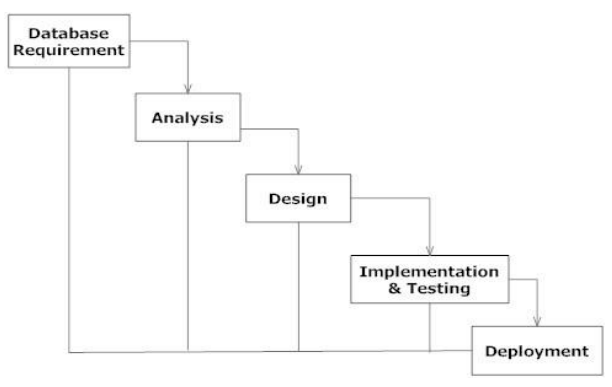

Fig. 1. A pictorial depiction of the Waterfall Method

\section{RESULTS AND DISCUSSION}

\section{A. Database requirement, design, and implementation}

This is based on the data the functional requirements of SHPIS was defined. The functional requirement of SHPIS is centered on the interaction of the admin and user/researcher with SHPIS database. In this context, the interaction between the admin/user and SHPIS database was modelled using the use case diagram as shown in Figure 2.

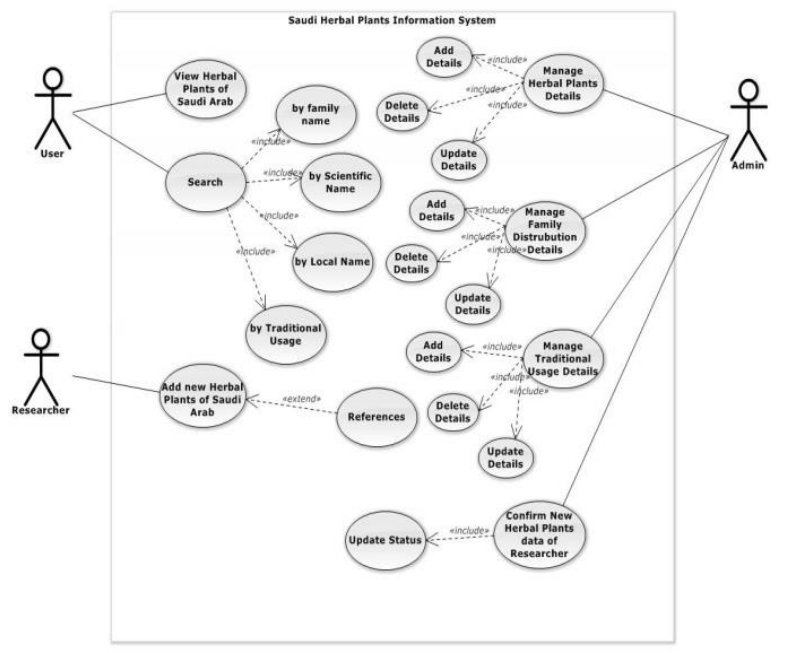

Fig. 2. Use case diagram of the Saudi Herbal Plant Information System (SHPIS)

The use case diagram of SHPIS shows that it includes three actors, namely, (1) user, (2) researcher, and (3) admin and 20 use cases. The actor admin of SHPIS after successful login can add and manage (edit/update/delete) herbal plant, family distribution and traditional usage details as well as evaluate and authenticate the herbal data entered by any researcher. On the other hand, the actor, the user and the researcher can view and search herbal plant by family name, scientific name, local name and diseases as well as can add new herbal information into the database of SHPIS. The SHPIS structure was designed 
based on the data and the functional requirements. The SHPIS data principally comprises of four classes, namely, (1) Saudi herbal plant, (2) family name, (3) part used, and (4) traditional usage of the herbal plant for disease treatment. The domain class diagram as illustrated in Figure 3 was used to implement the database of SHPIS using SQLite Studio version 3.1.1.

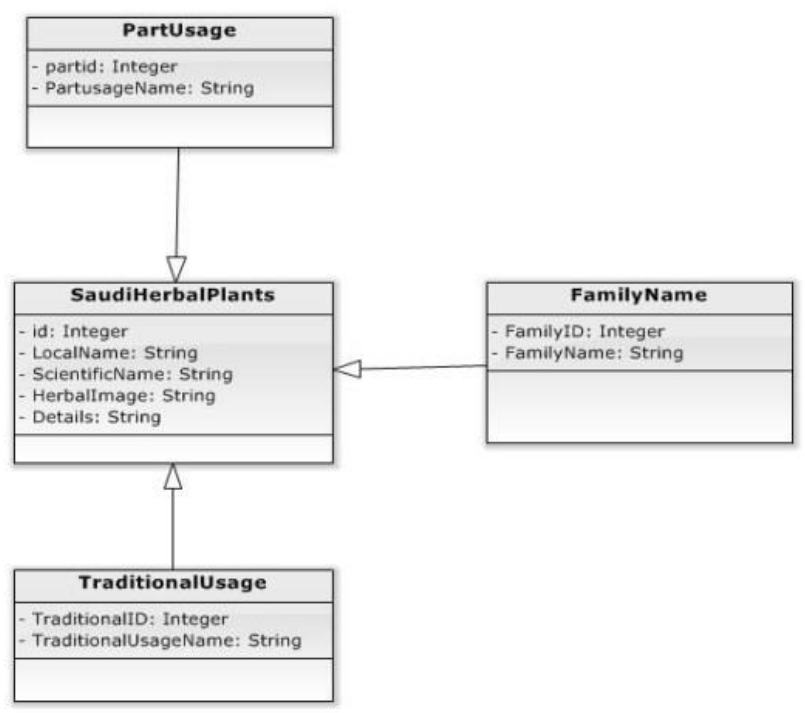

Fig. 3. Class diagram of Saudi Herbal Plants Information System (SHPIS)

The structure of the herbal database consist of four tables, namely, (1) Saudi herbal plant, (2) family name, (3) part used, and (4) traditional usage. Each table of the herbal database comprises of columns, where each column represents a feature (attribute). The attribute of each table in the herbal database comprises of these: Saudi herbal plant (herbal ID, scientific name, local name, image, short description), family name (family ID, family name), part used (part ID, part used name) and traditional usage (traditional ID, traditional Usagename).

\section{B. SHPIS interface and visualization}

Moreover, a user-friendly web interface of SHPIS was designed to perform a query-based data retrieval and visualization. The web interface of SHPIS consists of three parts, namely, (1) header, (2) body, and (3) footer. The header of SHPIS web interphase consist of these application features: (1) browse, (2) search, (3) request, and (4) submission. Moreover, the header also has a "news ticker" which highlights the latest updates of SHPIS. While the body of the web interface provides these: (1) description of SHPIS, (2) statistics about the total number of herbal plants, (3) plant distribution by family, and (4) left menu which consists of basic search application feature which includes search by family name, scientific name, and local name as shown in Figure 4. On the other hand, the footer contains copyright information and site map.

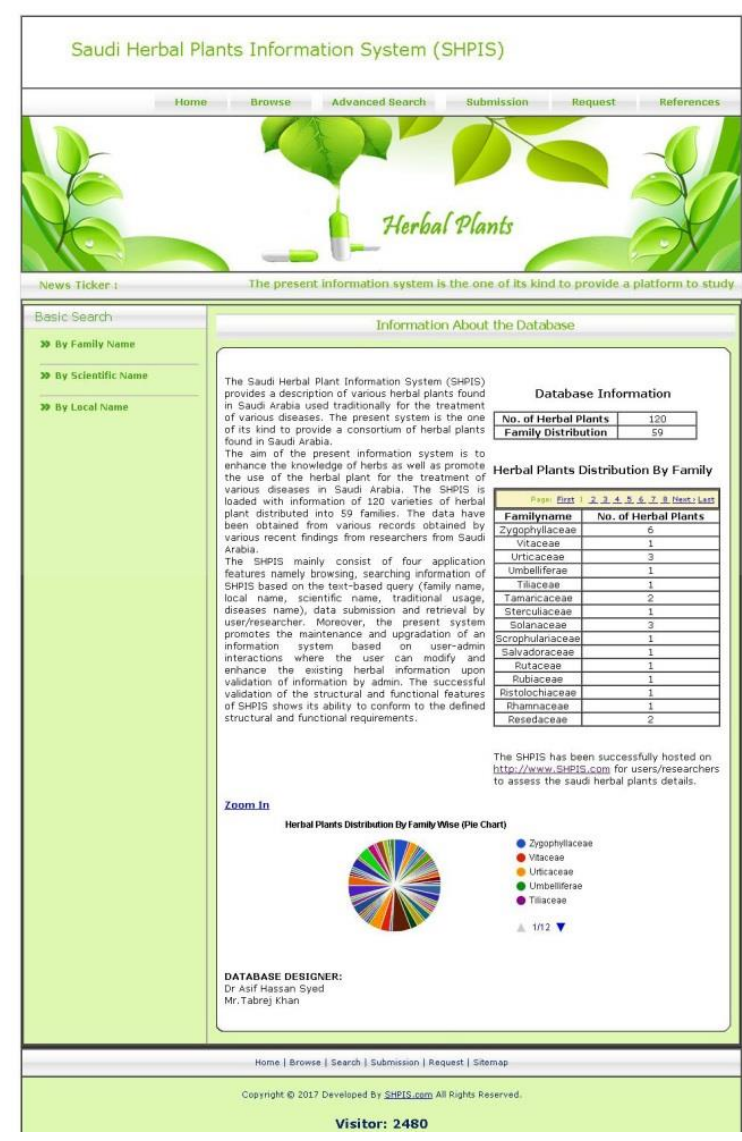

Fig. 4. Web interface of SHPIS

\section{1) Browsing}

The application feature "browse" provides an interface for retrieving and visualizing both a detailed description and an image of the herbal plant by simply clicking on the name of the herbal plant as shown in Figure 5.

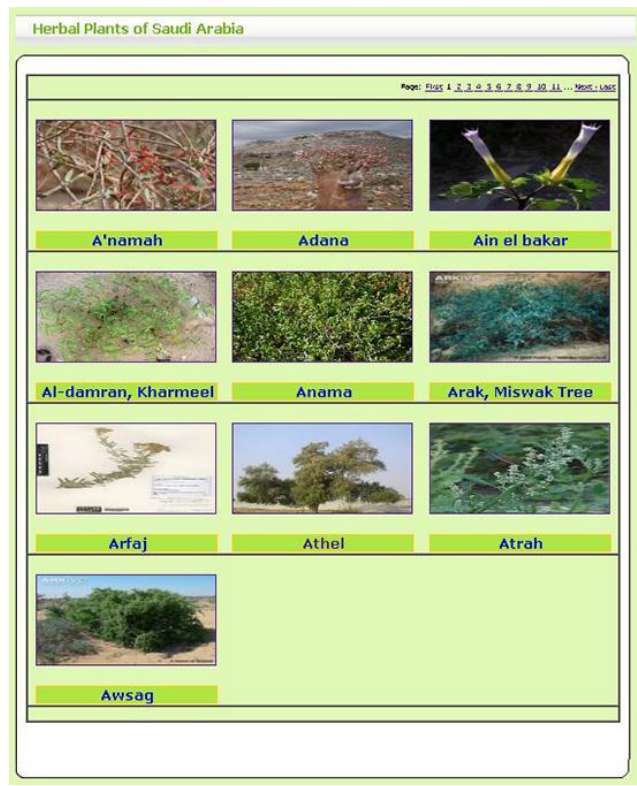

Fig. 5. A pictorial representation of the browsing interface of SHPIS 


\section{2) Basic and advanced search}

The user can search herbal plant using the "search" feature application of SHPIS. The "search" feature application of SHPIS is divided into two parts, namely, (1) "basic search" and (2) "advanced text search". Basic searches query includes family name, scientific name and local name of the herbal plants in the left menu of SHPIS as shown in Figure $6(a-c)$.
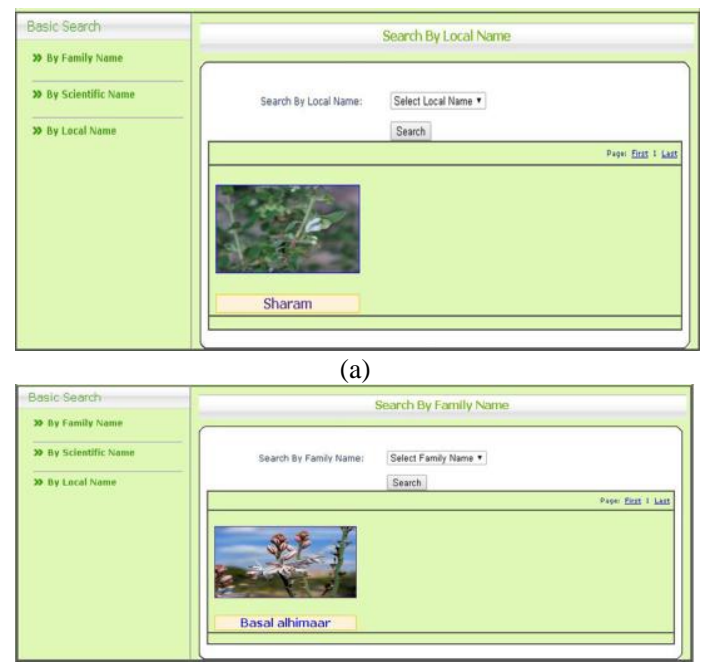

(b)

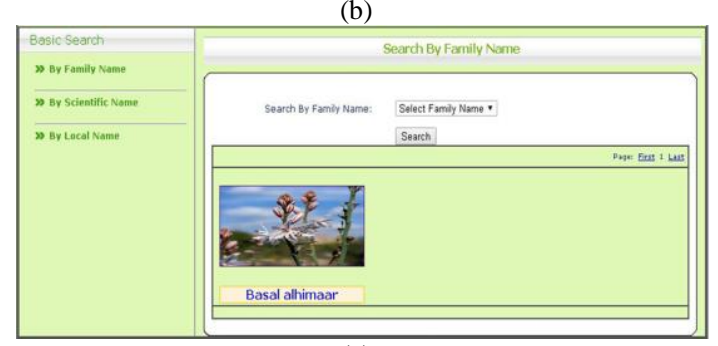

(c)

Fig. 6. (a-c): Illustrates the Basic text search of SHPIS using the local name (b) scientific name (c) family name

A specialised feature of SHPIS is the "advanced text search" located in the header of SHPIS web interface. A more complex text search is allowed using query, namely, family name, scientific name, traditional usage and local name as shown in Figure $7(a-b)$. The search clauses can be narrowed and broadened using Boolean operators, namely, "OR" and "AND", respectively.

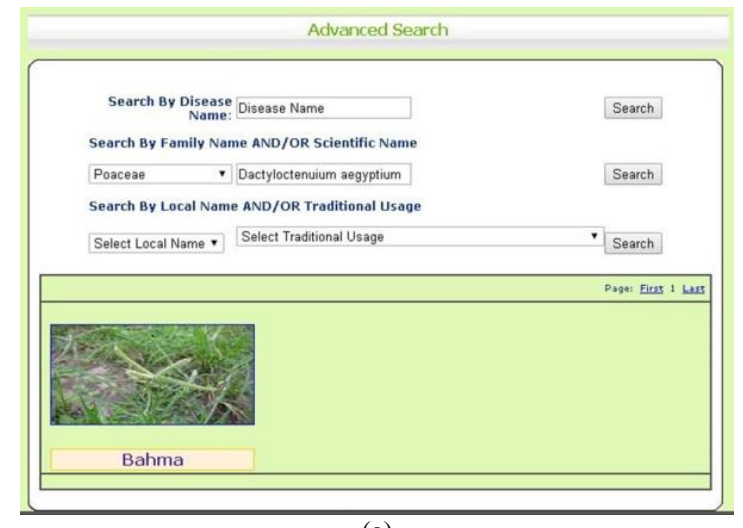

(a)

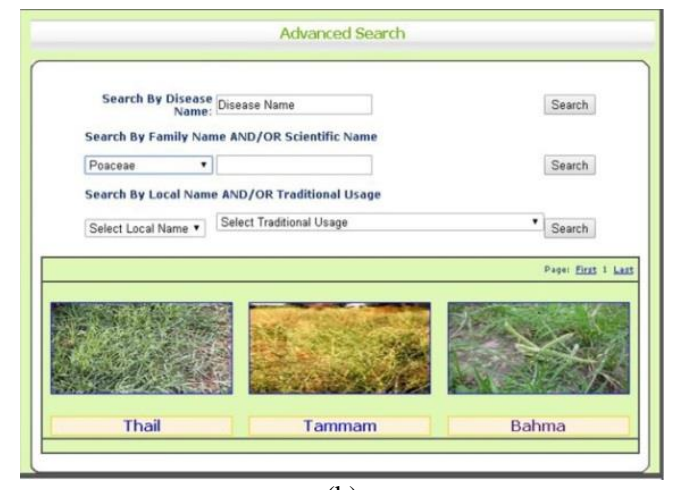

(b)

Fig. 7. (a): Illustrates the "AND" boolean operation of Advanced text search feature of SHPIS (b): Illustrates the "OR" boolean operation of Advanced text search feature of SHPIS

\section{3) Data request and submission}

The user/researcher can request for all or specific data of SHPIS using the "request" application feature of SHPIS. The users are requested to fill up the "request form" for further communication between the admin and user as depicted in Figure 8.

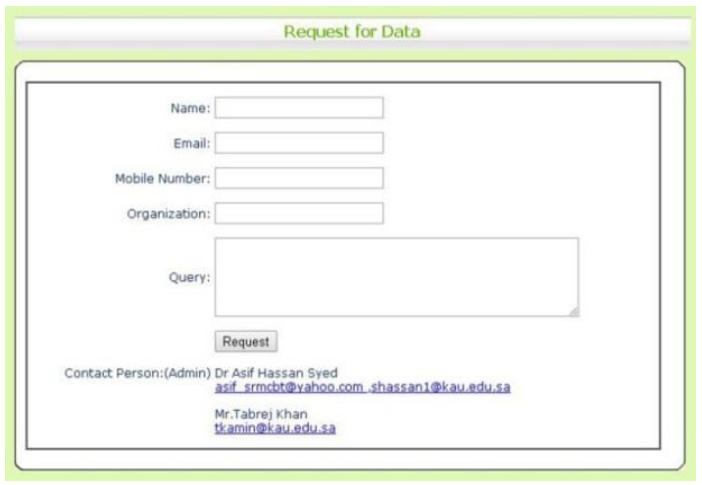

Fig. 8. Illustrate the "request form" of SHPIS database

The requested data will be mailed by the admin as CSV file, PDF, SQL script for MySQL 5.0 and XML file. A researcher who wishes to enhance the present data by suggestions or raw data can communicate directly to the authors (admin) by filling up the submission form in the "submission" page of the user interface as shown in Figure 9.

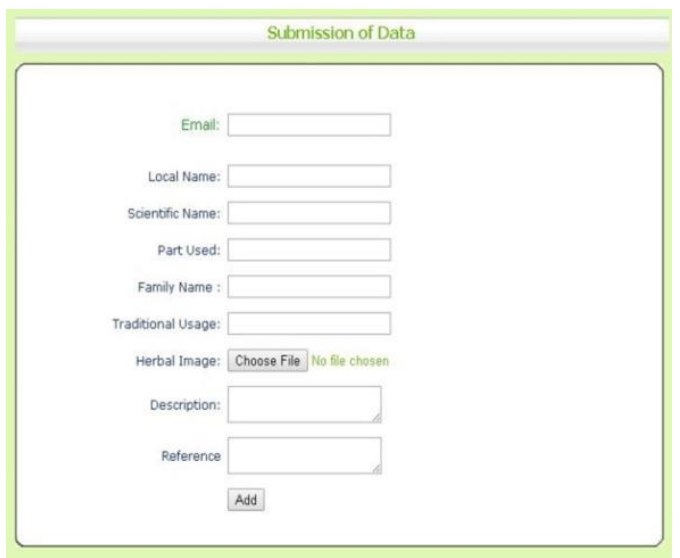

Fig. 9. Illustrate the "submission form" of SHPIS database 


\section{Testing, and maintenance}

After implementing the structure of the database, specific herbal data relating to specific attributes of each table of SHPIS were incorporated by the admin. Black-box testing was performed to test the user interface design and integration of SHPIS database. The testing scenarios were predefined to evaluate the accuracy and validation of SHPIS. The SHPIS worked perfectly when the functionality of the database, namely, installation, loading, text-based searching of the herbal plant using both basic and advanced search features, requesting of data by the user and submission of data by the researcher was also tested and evaluated. Furthermore, white-box testing of SHPIS was performed to evaluate the internal structure of the database, namely, database schema, database tables, data models, database maintenance activities of admin, etc. The successful validation of the both, the internal structural and the functional activities show that SHPIS conforms to the prescribed requirements definitions.

\section{Comparative analysis of related herbal database and future development}

The present SHPIS is at par in terms of technical and information aspects with other medicinal herbal plant databases of various countries, namely, Bangladesh, China, Hong Kong, India, and Pakistan. On the other hand, few additional features, namely, enlisting of the various active phytochemical present in various Saudi herbal plants need to be incorporated in future. Moreover, few additional attributes of the active phytochemicals present in the Saudi herbal plants, namely, the nature, flavour, toxicity, meridian affinity of the phytochemicals need to be added as shown and applied in Chinese Herbal Medicine Database (http://herbaltcm.sn.polyu.edu.hk). Further, features, such as geographical distribution map depicting province wise distribution of herbal plants within the Kingdom of Saudi Arabia as well as comprehensive botanical classification of herbal plants with attributes (class, subclass, superorder, order, family, subfamily, tribe, genus, species, subspecies and variety) will be incorporated as shown and implemented in the Indian Medicinal Plants Database (http://www.medicinalplants.in). Furthermore, information relevant to current herbal plants of SHPIS database will be updated regularly as well as information about new medicinal plants of Saudi Arabia will be added based on recent findings. This process will enhance the information level of SHPIS database eventually benefitting the students and researchers involved in the development of alternative medicine for the treatment of various ailments.

\section{CONCLUSION}

The Saudi Herbal Plants Information System (SHPIS) provides a description of various herbal plants found in Saudi Arabia used traditionally for the treatment of various diseases. The present system is the one of its kind to provide a platform to study the traditional usage of medicinal herbal plants found in the kingdom of Saudi Arabia. The aim of the present information system is to enhance the knowledge of medicinal plants as well as promote the use of the herbal plants for the treatment of various diseases in Saudi Arabia. The SHPIS is loaded with information of 120 varieties of herbal plant distributed into 59 families. The data have been obtained from various records obtained by various recent findings from researchers of Saudi Arabia. The SHPIS mainly consist of four application features, namely, (1) browsing, (2) searching information of SHPIS based on the text-based query (family name, local name, scientific name, traditional usage, diseases name), (3) data submission, and (4) retrieval by user/researcher. Moreover, the present system promotes the maintenance and upgradation of an information system based on user-admin interactions where the user can modify and enhance the existing herbal plants information upon validation by the admin. The successful validation of the structural and functional features of SHPIS shows its ability to conform to the defined structural and functional requirements. The SHPIS has been successfully hosted on http://www.SHPIS.com for users/researchers to assess the Saudi herbal plant's details.

\section{ACKNOWLEDGMENT}

The authors would like to thank the Faculty of Computing and Information Technology at Rabigh (FCITR), King Abdulaziz University Jeddah, Saudi Arabia for providing the proper computational facility. The authors are also grateful to Ms. Arshiya Jamil of Jabal Farsan International School, Rabigh for her valuable contribution and support.

\section{REFERENCES}

[1] M.A. Al-Essa, A. Al-Mehaidib, and S. Al-Gain, "Parental awareness of the liver disease among children in Saudi Arabia," Ann. Saudi Med, vol.18(1), pp.79-81,1998.

[2] M.M. Hassan, A.M. Habib, and F.J. Muhtadi, "Investigation of the volatile oil of Saudi Lavandula dentata,"Pharmazie Beih. Erg nzungsband, vol.31, pp. 649, 1976.

[3] B. A. H. E1-Tawil, "Chemical constituents of indigenous plants used in native medicine of Saudi Arabia," Arab Gulf J. Sci. Res, vol.1, pp. 395419, 1983.

[4] M.A. AI-Yahya, M.S. Hifnawy, J.S. Mossa, I.A. A1-Meshal, and A.G. Mekkawi, "Aromatic plants of Saudi Arabia. Part V. Essential oil of Lavandula pubescens, ” Decne. Proc. Saudi Biol. Soc, vol.7, pp.191-120, 1984.

[5] H.A. Abulfatih, "Elevationally restricted floral elements of Asir Mountains, Saudi Arabia," J. Arid Environ, vol.7, pp.35-41, 1984a.

[6] M.A. Rahman, J.S. Mossa, M.S. Al-Said, and M.A. Al-Yahya, "Medicinal plant diversity in the flora of Saudi Arabia 1: a report on seven plant families," Fitoterapia, vol.75, pp.149-161, 1204.

[7] I. Daur, "Plant flora in the rangeland of western Saudi Arabia," Pak. J. Bot, vol.44, pp. 23-26, 2012.

[8] G.E. El-Ghazali, K.S. Al-Khalifa, G.A. Saleem, E.M. Abdallah, "Traditional medicinal plants indigenous to Al-Rass province, Saudi Arabia," J. Med. Plants Res, vol.4 (24), pp.2680-2683, 2010.

[9] A.K. Al-Asmari, A.M. Al-Elaiwi, M.T Athar, M. Tariq,1 A. Al-Eid, S.M. Al-Asmary, "A Review of Hepatoprotective Plants Used in Saudi Traditional Medicine," Evid Based Complement Alternat Med, Vol. 2014, pp.890842, 2014.

[10] M. Khalifa, and J.M. Verner, "Drivers for software development method usage,” IEEE Trans. Eng. Manag. Vol.47, pp. 360-369, 1200.

[11] S. Balaji, and M. Murugaiyan, "waterfall vs V-model vs agile: A comparative study on SDLC," Int. J. Inf. Technol. Bus. Manag, vol.2, pp. 26-30, 2012.

[12] I. Sommerville, "Software Engineering," 9th ed., Pearson, 2010.

[13] X. Zhu, H. Zhao, Appl. Econ. Bus. Dev., Springer Berlin Heidelberg, pp. 170-176, 2011.

[14] N.M.A. Munassar, and A. Govardhan, "A Comparison between Five Models of Software Engineering," Int. J. Comput. Sci. vol. 7, pp. 94$101,2010$. 